\title{
Novel Nondestructive Measurement of Dye Adsorption on Solid Titania Films for Its Sensitized Solar Cells
}

\author{
Fahd M. Rajab ${ }^{1,2}$ \\ ${ }^{1}$ Promising Centre of Sensors and Electronic Devices, Najran University, Najran, Saudi Arabia \\ ${ }^{2}$ Department of Chemical Engineering, Najran University, Najran, Saudi Arabia \\ Email: fmrajab@najran.edu.sa \\ Received 4 February 2014; revised 7 March 2014; accepted 17 March 2014 \\ Copyright (C) 2014 by author and Scientific Research Publishing Inc. \\ This work is licensed under the Creative Commons Attribution International License (CC BY). \\ http://creativecommons.org/licenses/by/4.0/ \\ c) (i) Open Access
}

\begin{abstract}
A new nondestructive quantitative method is developed to measure the adsorption of dyes in solid titania films for dye-sensitized solar cells. UV-vis spectroscopy study showed that the absorbance of dye in the solid film can be directly related to the absorbance measured by the typical destructive method used to quantify concentration. Concentrations of N-719 and N-749 dyes on solid titania films were successfully extracted using molar extinction coefficients of dye on solid titania films with value of 6916 and $6454 \mathrm{~L} \cdot \mathrm{cm}^{-1} \cdot \mathrm{mol}^{-1}$ respectively determined using the spectral peaks at 512 and $586 \mathrm{~nm}$.
\end{abstract}

\section{Keywords}

UV-Vis Spectroscopy, Dye Adsorption, Titania, Solar Cells

\section{Introduction}

Dye-sensitized solar cells (DSSCs) are not limited by the high purities and, consequently, high capital costs associated with silicon-based devices [1]. In fact, DSSCs are promising devices for converting light to electricity at large scale because of their high efficiency, potential low-cost and simple assembly technology [2] [3]. These devices involve a chromophore sensitizer, typically a ruthenium-based dye, that harvests photons. Photons absorbed by the dye are excited to the lowest unoccupied molecular orbital, where an electron can then be injected into the conduction band of a large band gap semiconductor, which is typically titania. A majority of the research work on DSSCs has focused on the use of the photosensitive dyes $\mathbf{N}-719$ [bis(tetrabutylammonium)cis-di(thiocyanato)-N, NA-bis(4-carboxylato-4A-carboxylic acid-2,2A-bipyridine) ruthenium (II)] and N-749 
[(2,2':6',2”-terpyridine-4,4',4"'-tricarboxylate) ruthenium (II) tris (tetrabutylammonium) tris (isothiocyanate)].

The impregnation of the dye on the titania films occurs by soaking the matrix in a dye solution for several hours. The dye is adsorbed to the surface of titania by carboxylate groups that bind in different anchoring modes. It is important to obtain uniform dye coverage on titania to ensure enhanced electron transfer and low recombination rates. Excess dye loading can lead to multilayer formation, which causes quenching of the photoexcited electrons and leads to a reduction of charge injection. On the other hand, poor dye coverage leads to low photoactive surface area and an increased concentration of electron trap sites [4].

Although the dye is critical to the operation of DSSCs, often the dye concentration is not reported or correlated to device performance. The reason for this lack of such valuable information is that the dye concentration is typically obtained by dissolving the dye in a base solution, destroying the cell. The destructive analysis method is simple, but expensive dyes and devices are wasted in the process. In many cases, residual dye amounts remains in the films after completion of the dissolution step of the destructive method, introducing an inherent source of error in determining the concentration or dye coverage. In addition, the molar concentration of dye is also a significant parameter in models that describe the performance of DSSCs [5] [6]. Furthermore, obtaining accurate measurements of dye coverage is of importance for investigating the influence of dye solvents on the performance of DSSCs [7] [8].

In this paper, a new nondestructive method is developed to calculate the molar extinction coefficients of N-719 and N-749 dyes in titania films, and to quantify the dye concentration on films spanning a range of thicknesses. This technique has multiple benefits, including the possibility of enabling studies to establish a correlation of dye concentration with device performance without having to sacrifice functioning solar cells.

\section{Materials and Methods}

\subsection{Materials}

A paste containing $~ 18 \mathrm{wt} \%$ nanocrystalline titanium dioxide (Ti Nanoxide T/SP) as well as N-719 and N-749 Ruthenium-based dyes were purchased from Solaronix. The particle size of the titanium dioxide is reported to be $13 \mathrm{~nm}$. Fluorine-doped tin oxide films (FTO) on glass substrates were obtained precut. Acetonitrile and ethanol were purchased from Fisher Scientific. Sodium hydroxide (97\%) was purchased from Sigma Aldrich.

\subsection{Titania Film Preparation and Dye Impregnation}

Titania films of various thicknesses were pasted onto FTO substrates, as described previously [9]. Briefly, a titania paste is used to make 7, 10 and $20 \mu$ thick films (surface area of $0.384 \mathrm{~cm}^{2}$ ) using a simple doctor blade method. After the titania is pasted onto the FTO, the films are sintered in a tube furnace (Barnstead type 79,300 Thermolyne tube furnace) at a pressure of $5.3 \times 10^{-2} \mathrm{kPa}$ at $450^{\circ} \mathrm{C}$ for 30 minutes, and are then annealed at the same temperature on a hot plate until they become transparent. Finally, the films are cooled to room temperature at a controlled rate of $10^{\circ} \mathrm{C} / \mathrm{min}$. This method has been shown to prepare defect-free titania films for thicknesses ranging from 7 to $25 \mu \mathrm{m}$ [9]. Dye-solvent solutions of $0.3 \mathrm{mM}$ were prepared by dissolving $\mathbf{N - 7 4 9}$ and $\mathbf{N}-719$ dyes in acetonitrile and ethanol, respectively. Titania films were impregnated by soaking in the dye solution for times ranging between 18 to 48 hours.

\subsection{Determining the Molar Extinction Coefficient of the Dyes in a $\mathrm{NaOH}$ Solution}

The liquid extinction coefficient was obtained experimentally. The dyes N-719 and N-749 were dissolved in a mixture of $0.1 \mathrm{M}$ sodium hydroxide and ethanol (1:1 vol\%). UV-vis spectra were collected at different dye concentrations for each sample by further dilution with the $\mathrm{NaOH}$ solution. The $\mathrm{pH}$ values of the solutions were 13.09 and they did not change during dilution.

The absorbance at a spectral peak was plotted as a function of concentration, which yielded straight lines, as expected by Beer's Law. Applying Beer's law for the dye solution yields the relationship

$$
A_{\text {dye }}=\varepsilon_{\text {dye }} l C_{\text {dye }}
$$

where $A_{d y e}$ is the absorbance of the dye, $\varepsilon_{d y e}$ is the extinction coefficient of dye, $l$ is the path length of the optical cuvette $(1 \mathrm{~cm})$, and $C_{\text {dye }}$ is the molar dye concentration in the $\mathrm{NaOH}$ solution. The slope of the straight line defined by Equation (1) is the product $\varepsilon_{\text {dye }} l$, from which the extinction coefficient can be readily extracted. The experimental data with their corresponding straight-line fits are shown in Figure 1(a) and Figure 1(b). 

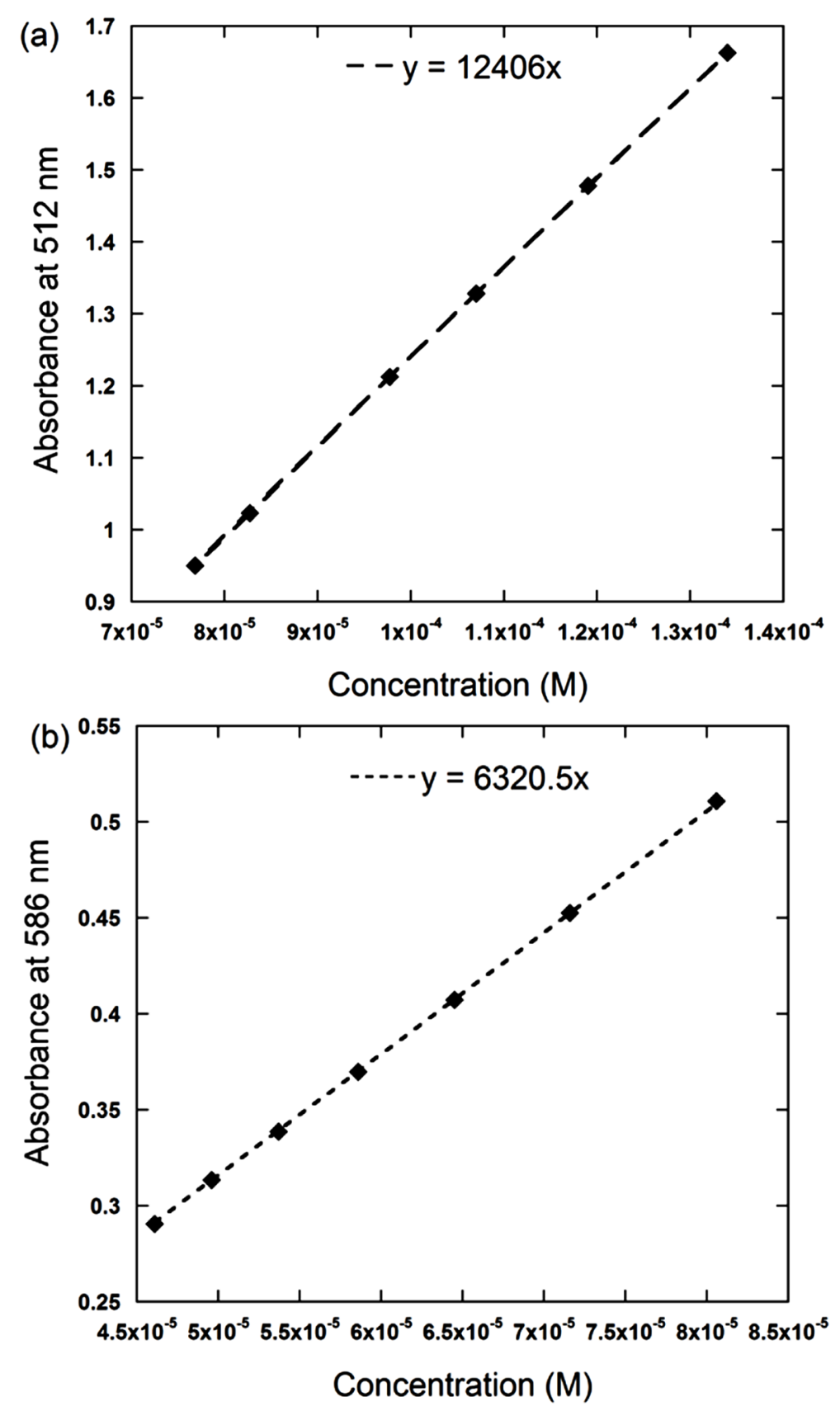

Figure 1. Absorbance spectra with their corresponding straight-line fits for determining the molar extinction coefficients in $\mathrm{NaOH}$ solutions for (a) $\mathrm{N}-719$ dye and (b) N-749 dye.

\subsection{Measurement of Molar Extinction Coefficients in the Solid State}

The thickness of titania films on FTO substrates were measured using surface profilometry and Scanning Electron Microscopy. Figure 2 shows the thickness of a titania film of $7 \mu \mathrm{m}$ using surface profilometry. Figure 3 shows the thickness of a titania film of $20 \mu \mathrm{m}$ using Scanning Electron Microscopy. UV-vis spectroscopy of the titania films or dye solutions were collected from 350 to $650 \mathrm{~nm}$ in a Perkin-Elmer Lambda 9 UV/VIS/NIR spectrometer. The spectra for dyes in the titania films were measured first. The titania films were mounted on an $\mathrm{X}-\mathrm{Z}$ translational stage (Newport), and multiple measurements ( 15) of the initial (unimpregnated) and impregnated titania film were obtained. The spectra of the initial and impregnated titania films were averaged for anal- 


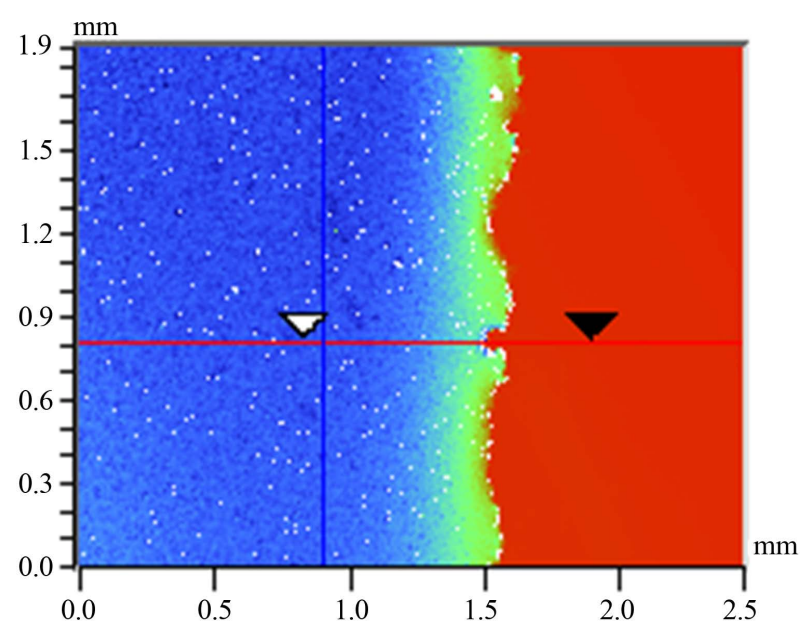

Figure 2. Surface Profilometryshows titania film thickness of $7 \mu \mathrm{m}$ on FTO substrate.

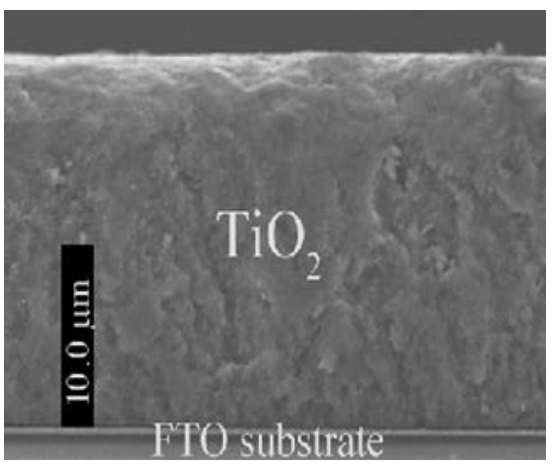

Figure 3. Scanning Electron Microscopyshows titania film thickness of $20 \mu \mathrm{m}$ on FTO substrate.

ysis. The titania films were then dissolved in $4 \mathrm{~mL}$ of $0.1 \mathrm{M}$ solution of $\mathrm{NaOH}$ in ethanol (1:1 vol\%) for $30 \mathrm{mi}-$ nutes for spectral analysis. It is worth noting that the spectra used to obtain the molar extinction coefficients were taken from a set of data that showed complete dissolution of the dye, with no residual dye remaining on the substrate.

\section{Results and Discussion}

Figure 4 shows the absorption spectra for $\mathbf{N - 7 1 9}$ and $\mathbf{N - 7 4 9}$ dyes in the $\mathrm{NaOH}$ solution and in the solid titania films. The solid line in Figure 4(a) displays the characteristic peaks of the $\mathbf{N - 7 1 9}$ dye at 375 and $512 \mathrm{~nm}$ in an $\mathrm{NaOH}$ solution, while the solid line in Figure 4(b) shows the characteristic peaks of the N-749 dye at 397 and $586 \mathrm{~nm}$. Figure 4(a) and Figure 4(b) demonstrate that the spectra for each dye red-shifts once they are adsorbed onto the titania films. For example, the peaks used to determine the molar extinction coefficients of each dye shifted to 525 and $620 \mathrm{~nm}$ for $\mathbf{N - 7 1 9}$ and $\mathbf{N}-\mathbf{7 4 9}$, respectively. Shifts in peak position can be expected because of the effect of the localized environment on the excited state [10]. Table 1 shows the molar extinction coefficients of each dye in the $\mathrm{NaOH}$ solution using the 512 and $586 \mathrm{~nm}$ peaks for $\mathbf{N - 7 1 9}$ and $\mathbf{N - 7 4 9}$, respectively.

Although the spectra of each dye adsorbed onto the titania has shifted, Beer's Law can still be used to measure the concentration, provided there are no other optical effects that alter the transmission of light. Figure 5 shows the absorbance for each dye measured in the $\mathrm{NaOH}$ solution and in solid titania. The slope of each straight line in Figure 5 yields the absorbance ratio $A_{\text {dye, } \ell} / A_{d y e, s}$, where the subscripts $\ell$ and $s$ correspond to the liquid $\mathrm{NaOH}$ and solid titania film, respectively. This ratio equals $\sim 3$ and $\sim 9$ for the N-719 and N-749 dyes, respectively. The linearity of the plots indicates that ancillary optical effects are negligible. 

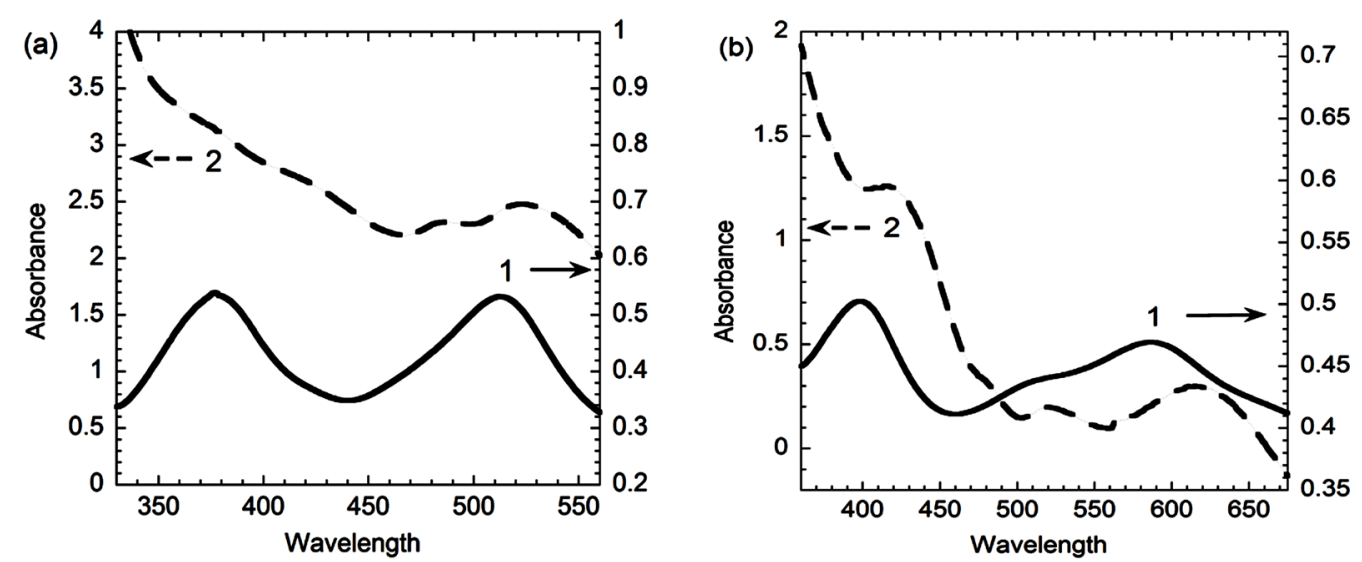

Figure 4. Absorbance spectra for (a) N-719 and (b) N-749 dyes in an NaOH solution (solid line, marker “1”) and in solid titania (dashed line, marker “2”).

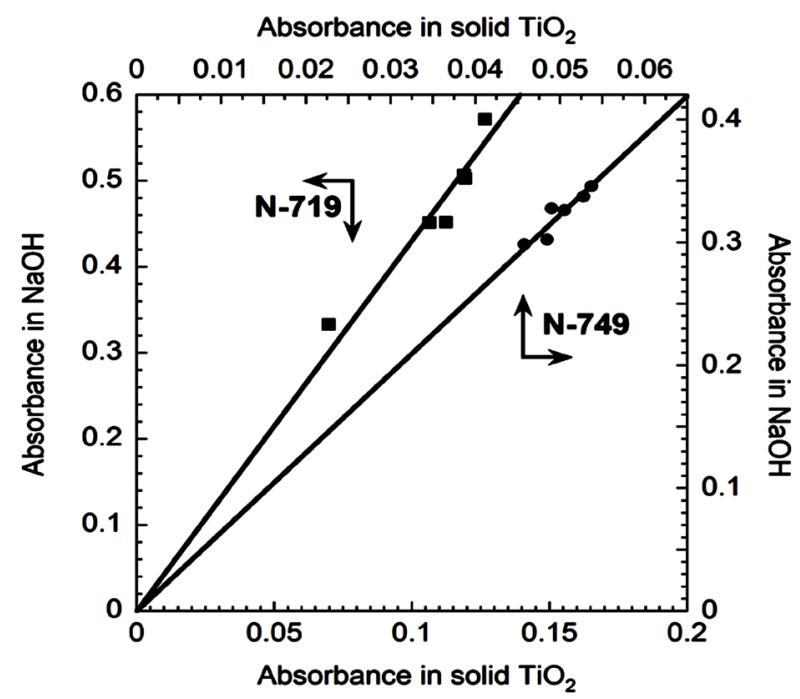

Figure 5. Absorbance of N-719 (square markers) and N-749 (circle markers) dyes or dissolved in $\mathrm{NaOH}$ and adsorbed onto the solid titania film.

Table 1. Measured molar extinction coefficients $\varepsilon$ for each dye in an $\mathrm{NaOH}$ solution and in a solid titania film. The wavelength $\lambda$ of the spectral peaks used for calculation of the extinction coefficients are shown.

\begin{tabular}{ccccc}
\hline & \multicolumn{2}{c}{ N-719 dye } & \multicolumn{2}{c}{ N-749 dye } \\
\hline & $\lambda(\mathrm{nm})$ & $\varepsilon\left(\mathrm{L} \cdot \mathrm{cm}^{-1} \cdot \mathrm{mol}^{-1}\right)$ & $\lambda(\mathrm{nm})$ & $\varepsilon\left(\mathrm{L} \cdot \mathrm{cm}^{-1} \cdot \mathrm{mol}^{-1}\right)$ \\
\hline NaOH solution $(\ell)$ & 512 & 12406 & 586 & 6321 \\
titania film $(s)$ & 525 & 6916 & 620 & 6454 \\
\hline
\end{tabular}

It is now convenient to rewrite Beer's Law (1) in the equivalent form

$$
A_{d y e}=\varepsilon_{\text {dye }} l \frac{N_{\text {dye }}}{V}
$$

where $N_{\text {dye }}$ is number of moles of dye and $V$ is the volume of the medium hosting the dye. In the suite we introduced the subscript $\ell$ in the notation $\varepsilon_{d y e}=\varepsilon_{d y e, \ell}$ and $A_{d y e}=A_{d y e, \ell}$ to denote the absorbance and extinction coefficient of the dye in the liquid $\mathrm{NaOH}$ solution. Analogously, we introduce the subscripts to denote the 
analogous quantities in the solid titania films. It should be noted that both the absorbance and the extinction coefficient are functions of the wavelength. If the dye adsorbed onto the titania film is dissolved completely in the $\mathrm{NaOH}$ solution, then the number of moles of dye in the $\mathrm{NaOH}$ solution (denoted $N_{\text {dye, } \ell}$ ) must be equal to the number of moles in the solid titania film ( $N_{\text {dye,s }}$ ). This observation leads to the equalities

$$
N_{\text {dye }, \ell}=\frac{A_{d y e, \ell} V_{\ell}}{\varepsilon_{\text {dye }, \ell} l}=\frac{A_{\text {dye }, \mathrm{s}} V_{s}}{\varepsilon_{\text {dye }, \mathrm{s}} t}=N_{\text {dye }, \mathrm{s}}
$$

where $t$ is the thickness of the titania film.

By rearranging Equation (3) and writing $V_{s}=t a_{s}$, where $a_{s}$ is the planar surface area of the film and $t$ the film thickness, the following expression for the molar extinction coefficient of the dye adsorbed onto the solid titania films is obtained:

$$
\varepsilon_{d y e, s}=\left(\frac{A_{d y e, s}}{A_{d y e, \ell}}\right) l\left(\frac{a_{s}}{V_{\ell}}\right) \varepsilon_{d y e, \ell}
$$

Equation (4) shows that the molar extinction coefficient for the dye adsorbed onto the titania films, $\varepsilon_{d y e, s}$, is a function of the constants $l, a_{s}, V_{\ell}$, and $\varepsilon_{\text {dye } \ell}$, and of the ratio of dye absorbances $A_{\text {dye }, s} / A_{\text {dye }, \ell}$. Furthermore, Equation (4) is the basis for the new nondestrictuve technique for dye concentration analysis advanced in this work. The quantities bearing the subscript $l$ on the right-hand side of the equation can be obtained by carrying out measurements on standard liquid solutions prepared with known dye concentrations in a $\mathrm{NaOH}$ sample. The quantities bearing the subscript $s$ refer to the solid titania film, and can be measured in a nondestructive fashion.

Equation (4) was then used to determine the molar extinction coefficients of each dye adsorbed onto the titania films, as reported in Table 1. These molar extinction coefficients can be used to calculate the concentration of dye adsorbed onto the titania film. As shown in Figure 6, the molar extinction coefficients obtained using Equation (4) are able to accurately determine the amount of dye adsorbed at a variety of concentrations and film thicknesses.

\section{Conclusion}

The molar extinction coefficients of both $\mathbf{N - 7 1 9}$ and N-749 dyes adsorbed onto titania were determined. These

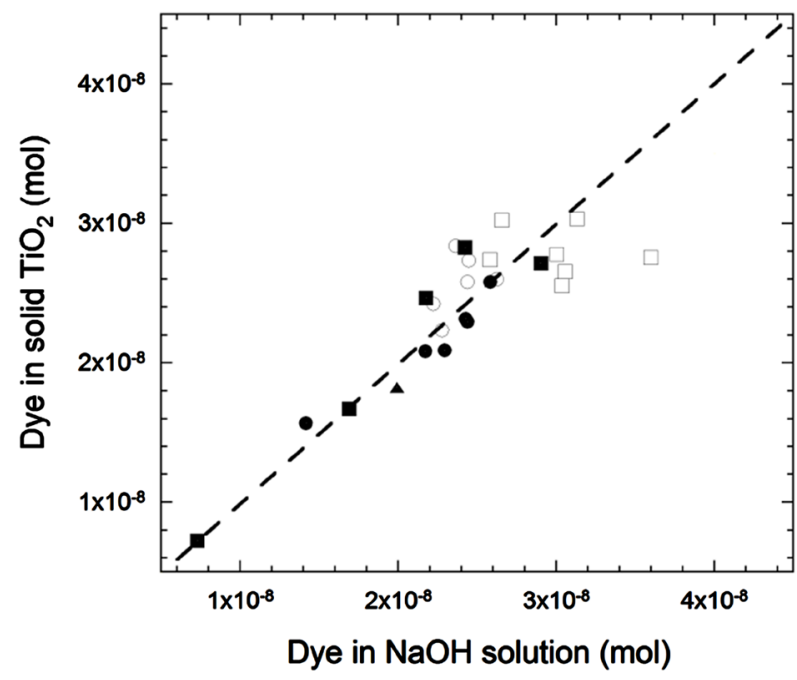

Figure 6. Comparison of the concentration of N-719 (open markers) and N-749 (solid makers) dye determined by measuring the absorbance in the solid state or $\mathrm{NaOH}$ solution for titania films ranging in thickness from 7 to $20 \mu \mathrm{m}$. The circle markers denote $7 \mu \mathrm{m}$, the square markers $10 \mu \mathrm{m}$ and the triangle markers $20 \mu \mathrm{m}$ thick films. The dashed line represents equimolar values. 
molar extinction coefficients can be used to determine the concentration of dye adsorbed in films of varying thickness without destroying the film. This nondestructive technique provides an accurate measurement of the dye adsorbed onto titania. The new technique presented in this work opens up opportunities for future research directions, for example, conducting studies that seek to relate dye concentration with internal quantum efficiency of DSSCs without destroying the devices.

\section{Acknowledgements}

The author would like to acknowledge the support of the Ministry of Higher Education, Kingdom of Saudi Arabia for this research through a grant (PCSED-004-11) under the Promising Center for Sensors and Electronic Devices (PCSED) and a grant (NU 54/12) under the deanship of scientific research at Najran University, Kingdom of Saudi Arabia. The author acknowledges insights provided by Prof. K.J. Ziegler at University of Florida, and funding received from the National Science Foundation. Doctor blades were donated by the Incision Tech Company.

\section{References}

[1] Gratzel, M. (2006) The Advent of Mesoscopic Injection Solar Cells. Progress in Photovoltaics, 14, 429-442. http://dx.doi.org/10.1002/pip.712

[2] Johansson, E.M.J., Hedlund, M., Siegbahn, H. and Rensmo, H. (2005) Electronic and Molecular Surface Structure of Ru(tcterpy)(NCS)(3) and Ru(dcbpy)(2)(NCS)(2) Adsorbed from Solution onto Nanostructured $\mathrm{TiO}_{2}$ : A Photoelectron Spectroscopy Study. Journal of Physical Chemistry B, 109, 22256-22263. http://dx.doi.org/10.1021/jp0525282

[3] Nazeeruddin, M.K., Humphry-Baker, R., Liska, P. and Grätzel, M. (2003) Investigation of Sensitizer Adsorption and the Influence of Protons on Current and Voltage of a Dye-Sensitized Nanocrystalline $\mathrm{TiO}_{2}$ Solar Cell. The Journal of Physical Chemistry B, 107, 8981-8987. http://dx.doi.org/10.1021/jp022656f

[4] Adachi, M., Sakamoto, M., Jiu, J., Ogata, Y. and Isoda, S. (2006) Determination of Parameters of Electron Transport in Dye-Sensitized Solar Cells Using Electrochemical Impedance Spectroscopy. Journal of Physical Chemistry B, 110, 13872-13880. http://dx.doi.org/10.1021/jp061693u

[5] Ono, T., Yamaguchi, T. and Arakawa, H. (2010) Influence of Dye Adsorption Solvent on the Performance of a Mesoporous $\mathrm{TiO}_{2}$ Dye-Sensitized Solar Cell Using Infrared Organic Dye. Journal of Solar Energy Engineering, 132, Article ID: 021101. http://dx.doi.org/10.1115/1.4001171

[6] O’Regan, B. and Grätzel, M. (1991) A Low-Cost, High-Efficiency Solar Cell Based on Dye-Sensitized Colloidal TiO 2 Films. Nature, 353, 737-740. http://dx.doi.org/10.1038/353737a0

[7] Penny, M., Farrell, T. and Please, C. (2008) A Mathematical Model for Interfacial Charge Transfer at the Semiconductor-Dye-Electrolyte Interface of a Dye-Sensitised Solar Cell. Solar Energy Materials \& Solar Cells, 92, 11-23. http://dx.doi.org/10.1016/j.solmat.2007.07.013

[8] Penny, M., Farrell, T. and Will, G. (2008) A Mathematical Model for the Anodic Half Cell of a Dye-Sensitised Solar Cell. Solar Energy Materials \& Solar Cells, 92, 24-37. http://dx.doi.org/10.1016/j.solmat.2007.07.012

[9] Rajab, F.M., Loaring, D. and Ziegler, K.J. (2011) Preparing Thick, Defect-Free Films of Anatase Titania for Dye-Sensitized Solar Cells. Thin Solid Films, 519, 6598-6604. http://dx.doi.org/10.1016/j.tsf.2011.04.171

[10] Suppan, P. and Ghoneim, N. (1997) Solvatochromism. The Royal Society of Chemistry, Cambridge. 